Article

\title{
Effect of Phyllanthus amarus Extract on 5-Fluorouracil-Induced Perturbations in Ribonucleotide and Deoxyribonucleotide Pools in HepG2 Cell Line
}

\author{
Jian-Ru Guo ${ }^{1}$, Qian-Qian Chen ${ }^{1}$, Christopher Wai-Kei Lam ${ }^{1}$, Cai-Yun Wang ${ }^{1}$, Feng-Guo Xu ${ }^{2}$, \\ Bu-Ming Liu $^{3, *,+}$ and Wei Zhang ${ }^{1, *,+}$ \\ 1 State Key Laboratory of Quality Research in Chinese Medicines, Macau Institute for Applied Research in \\ Medicine and Health, Macau University of Science and Technology, Taipa, Macau SAR, China; \\ guojianrumust@gmail.com (J.-R.G.); qqchen@must.edu.mo (Q.-Q.C.); wklam@must.edu.mo (C.W.-K.L.); \\ cywang@must.edu.mo (C.-Y.W.) \\ 2 Key Laboratory of Drug Quality Control and Pharmacovigilance (Ministry of Education), China \\ Pharmaceutical University, Nanjing 210009, China; fengguoxu@cpu.edu.cn \\ 3 Guangxi Key Laboratory of Traditional Chinese Medicine Quality Standards, Guangxi Institute of \\ Traditional Medical and Pharmaceutical Sciences, Nanning 530022, China \\ * Correspondence: liubuming@aliyun.com (B.-M.L.); Wzhang@must.edu.mo (W.Z.); \\ Tel.: +86-771-588-3405 (B.-M.L.); +853-8897-2463 (W.Z.); \\ Fax: +86-771-586-7737 (B.-M.L.); +853-2882-5886 (W.Z.) \\ + These authors contributed equally to this work.
}

Academic Editor: Derek J. McPhee

Received: 16 August 2016; Accepted: 14 September 2016; Published: 20 September 2016

\begin{abstract}
The aim of this study was to investigate the antitumor activities of Phyllanthus amarus (PHA) and its potential of herb-drug interactions with 5-Fluorouracil (5-FU). Cell viability, ribonucleotides (RNs) and deoxyribonucleotides (dRNs) levels, cell cycle distribution, and expression of thymidylate synthase (TS) and ribonucleotide reductase (RR) proteins were measured with 3-(4,5-dimethylthiazol-2-yl)-2,5-diphenyltetrazolium bromide (MTT) assay, high performance liquid chromatography tandem mass spectrometry (HPLC/MS/MS) method, flow cytometry and Western blot analysis, respectively. Our standardized PHA extract showed toxicity to HepG2 cells at high concentrations after $72 \mathrm{~h}$ exposure and induced G2/M cell cycle arrest. Combined use of 5-FU with PHA resulted in significant decreases in ATP, CTP, GTP, UTP and dTTP levels, while AMP, CMP, GMP and dUMP levels increased significantly compared with use of 5-FU alone. Further, PHA could increase the role of cell cycle arrest at $\mathrm{S}$ phase induced by 5-FU. Although PHA alone had no direct impact on TS and RR, PHA could change the levels of RNs and dRNs when combined with 5-FU. This may be due to cell cycle arrest or regulation of key enzyme steps in intracellular RNs and dRNs metabolism.
\end{abstract}

Keywords: Phyllanthus amarus extract; 5-fluorouracil; ribonucleotides; deoxyribonucleotides

\section{Introduction}

Nucleoside analogs (NAs) have been developed for almost 50 years for treating cancers or viral infections [1]. NAs usually produce their major therapeutic effects through inhibition of DNA and RNA synthesis, regulation of key intracellular enzymes, and interference with cell signaling and intracellular metabolisms. These action mechanisms inevitably affect the natural ribonucleotides (RNs) and deoxyribonucleotides (dRNs) pool sizes, which play important roles in broad cellular functions such as DNA replication, proliferation and cell cycling [2,3]. Strategies to optimize intracellular 
RNs and dRNs pool sizes provide opportunities to potentiate antitumor effects of NAs and enhance cancer-cell selectivity, which have been proven beneficial in clinical trials $[4,5]$.

5-Fluorouracil (5-FU) is a fluoropyrimidine anticancer agent that has been widely used to treat many types of cancers such as colorectal, liver and breast cancers [6-8]. Since its active metabolite, 5-fluoro-2'-deoxyuridine-5'-monophosphate (FdUMP), is an irreversible inhibitor of thymidylate synthase (TS), 5-FU incubation could lead to decrease of intracellular deoxythymidine triphosphate (dTTP) and increase of deoxyuridine monophosphate (dUMP) $[9,10]$. Meanwhile, other intracellular RNs and dRNs pool sizes were also perturbed by 5-FU due to complex metabolic networks of RNs and dRNs. In turn, the perturbation of RNs and dRNs could affect the action of 5-FU and its activity.

Recently, there has been increasing interest worldwide in using herbal medicine combined with conventional chemotherapeutic agents for improving chemotherapeutic activity [11]. Many herbal medicines that can act as adjuvants for cancer therapeutics were found to enhance the efficacy of anti-cancer drugs as well as reducing the side effects and chemo-resistances [12]. Phyllanthus amarus (PHA) is a Chinese herbal medicine that has been used to treat various diseases including jaundice, dysentery, disorders, scabies and wounds [13]. There are various pathogens, toxins and risk factors leading to hepatocellular carcinoma, including hepatitis B virus (HBV), hepatitis $C$ virus (HCV), alcohol, aflatoxin-B, diabetes, obesity, and non-alcoholic fatty liver disorders (NAFLD) [14-17]. PHA has a potential for treating hepatocellular carcinoma because it has been found to inhibit DNA polymerase of HBV and related hepatitis viruses and down regulate HBV mRNA transcription and translation [18-20]. In actual practice, cancer patients may receive PHA as adjuvant therapy intentionally or unintentionally, although the authorized information on its activity is not plentiful in the literature. Extracts of PHA could inhibit cytochromes P450 (CYP) CYP1A2, CYP2D6, CYP2E1 and CYP3A4 in a dose-dependent manner and thus raise the potential of herb-drug interactions. However, enzymes from the CYP family usually are not involved in metabolism of NAs [21]. Meanwhile, TS represents a critical target in cancer chemotherapy. Thus, it is critical to learn the possible pharmacokinetic interactions between PHA and 5-FU or other NAs since NAs are clinically important anticancer, anti-HBV and anti-HIV agents.

In this study, the cytotoxic effect of a chemically standardized PHA extract and the effect of this extract on 5-FU-induced perturbations in RNs and dRNs pool sizes were investigated in human hepatocellular carcinoma (HepG2) cells. Our results showed that high dosage and long treatment duration of PHA extract exerted a cytostatic effect on HepG2 cells. Meanwhile, low dosage of PHA also has a slightly synergistic effect and perturbation on RNs and dRNs pool sizes when combined with 5-FU.

\section{Results and Discussion}

\subsection{Standarization of PHA Extract}

PHA mainly contains lignans, triterpenes, alkaloids, and tannins and other components such as flavonoids, lactones and steroids [14]. Although Corilagin has been used as a marker compound, it seems to be insufficient to assess the quality of Phyllanthus [22]. We have developed An HPLC/TOFMS method together with chemometric methods has been developed for the quality assessment of Phyllanthus collected from different species and geographical locations [23]. A total of 59 compounds were identified and tentatively assigned structures from PHA extract by previously published method. By comparing the retention time and MS data with those of reference compounds, the contents of protocatechuic acid, corilagin, caffeic acid, ellagic acid, rutin, quercetin, luteolin, kaempferol, phyllanthin, niranthin, oleanolic acid, palmitic acid in the PHA were 3.91, 295.2, 15.2, $574.2,217.7,92.3,0.10,0.20,792.3,260.98,16.3$ and $12.9 \mu \mathrm{g} / \mathrm{g}$, respectively.

\subsection{Effect of PHA Extract on Growth of HepG2 Cells}

In order to study the inhibition of PHA extract on cell growth, HepG2 cells were exposed to PHA extract at various concentrations $(1.56,3.13,6.25,12.5,25.0,50.0,100.0$ and $150.0 \mu \mathrm{g} / \mathrm{mL})$ over different 
incubation periods (24, 48 and $72 \mathrm{~h}$ ). High dosage and longtime treatment with PHA extract could inhibit proliferation of HepG2 (Figure 1A). The $\mathrm{IC}_{50}$ value of PHA extract on inhibition of HepG2 cells growth at $72 \mathrm{~h}$ was $114.0 \pm 24.6 \mu \mathrm{g} / \mathrm{mL}$. Furthermore, at low cytotoxicity dosage $(50.0 \mu \mathrm{g} / \mathrm{mL}), \mathrm{PHA}$ extract could also enhance cytotoxic activity of 5-FU but not significantly. Namely, exposure to 5-FU $(50.0 \mu \mathrm{M})$ combined with $50.0 \mu \mathrm{g} / \mathrm{mL}$ PHA extract for $48 \mathrm{~h}$ decreased cell viability of HepG2 cells from $71.26 \% \pm 3.93 \%$ to $54.66 \% \pm 2.56 \%$ (Figure $1 \mathrm{~B}, p<0.01$ ). At the same time, the value of combination index (CI) was 0.66 (Table 1). This suggests that there was a slightly synergy between these two drugs according to the data of cell viability and the value of $\mathrm{CI}$.

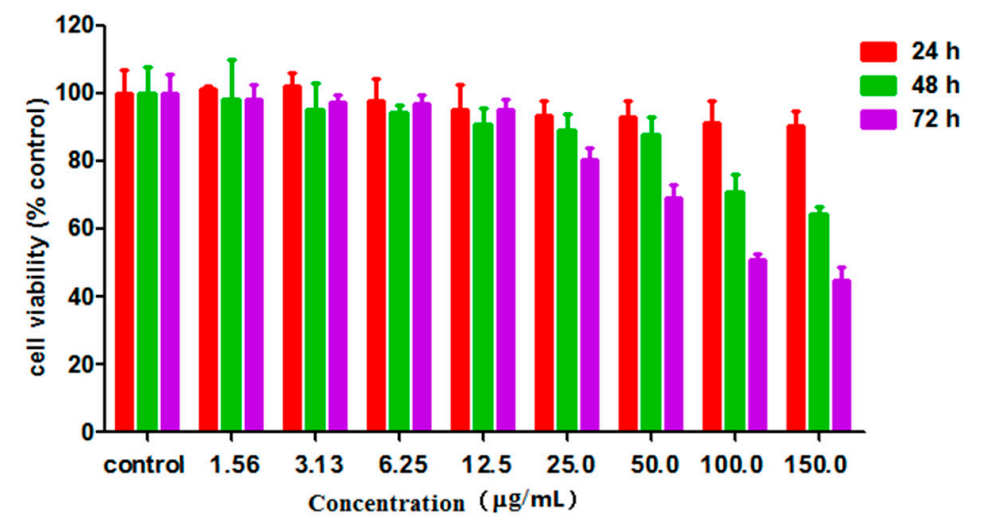

A

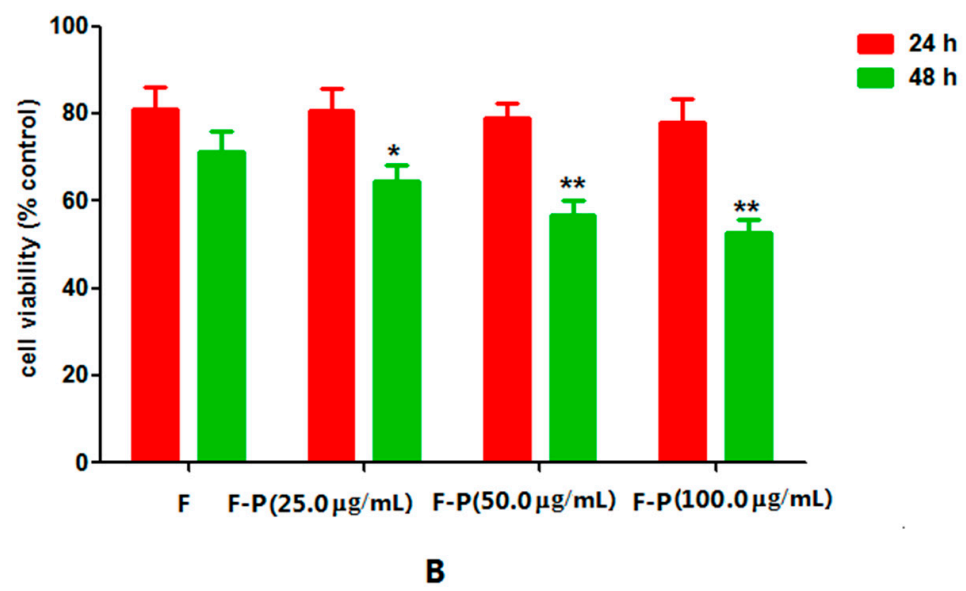

Figure 1. MTT results: (A) Cell viability of HepG2 cancer cells treated with different concentration of PHA for 24, 48 and $72 \mathrm{~h}$; and (B) cell viability of combination treatment of 5-FU and PHA $\left({ }^{*} p<0.05\right.$, ** $p<0.01$, versus the 5-FU group).

Table 1. The combination index (CI) values of combination treatment of 5-FU and PHA in HepG2 cells.

\begin{tabular}{cccc}
\hline \multirow{2}{*}{ Time (h) } & \multicolumn{3}{c}{ PHA $(\boldsymbol{\mu g} / \mathrm{mL})$} \\
\cline { 2 - 4 } & $\mathbf{2 5 . 0}$ & $\mathbf{5 0 . 0}$ & $\mathbf{1 0 0 . 0}$ \\
\hline 24 & 1.16 & 1.23 & 1.37 \\
48 & 0.76 & 0.66 & 0.71 \\
\hline
\end{tabular}

\subsection{Multivariate Statistical Analysis}

In order to understand and visualize the grouping trends, unsupervised principal component analysis (PCA) and supervised orthogonal partial least squares discriminant analysis (OPLS-DA) were performed using SIMCA-P version 14.0 software (Umetrics, Sweden). As shown in Figure 2A,B, clear group separation of sample points suggested that exposure to 5-FU with or without PHA extract made 
a significant difference in the profiles of RNs and dRNs pools, although PHA extract alone has no impact on intracellular RNs and dRNs pool sizes. Further, it can be seen from the OPLS-DA model in Figure 2C,D that $\mathrm{F}$ group and P-F group seemed easily classified into two groups with satisfactory discriminating ability, which suggested that PHA was able to stimulate the perturbation of RNs and dRNs levels induced by 5-FU. Finally, six RNs and dRNs including adenosine-triphosphate (ATP), cytidine triphosphate (CTP), guanosine triphosphate (GTP), uridine triphosphate (UTP), dUMP and dTTP were screened out using VIP $>1.0$ and $p<0.05$ (Figure 2E,F).

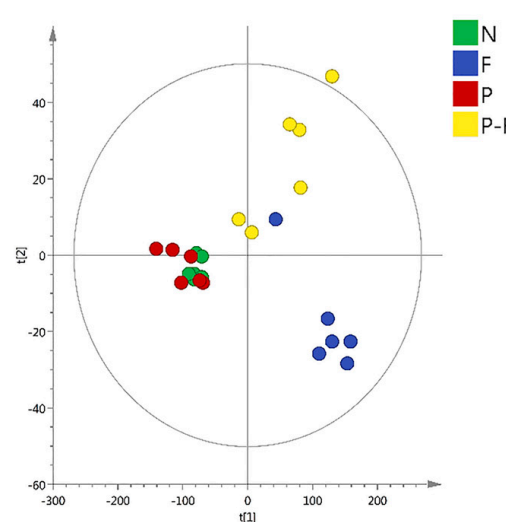

A

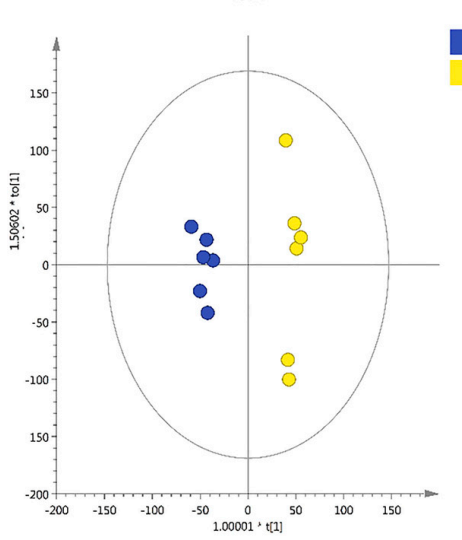

C

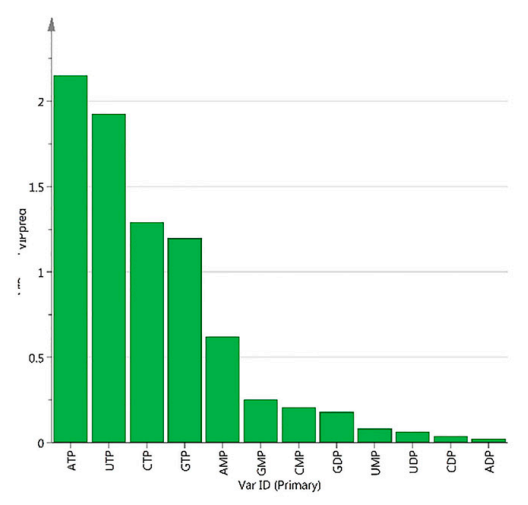

$\mathbf{E}$

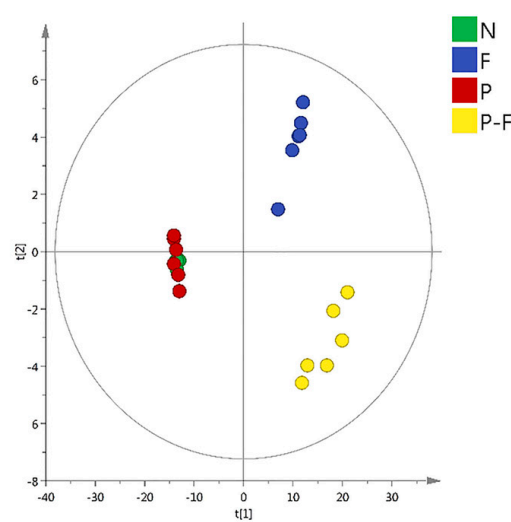

B

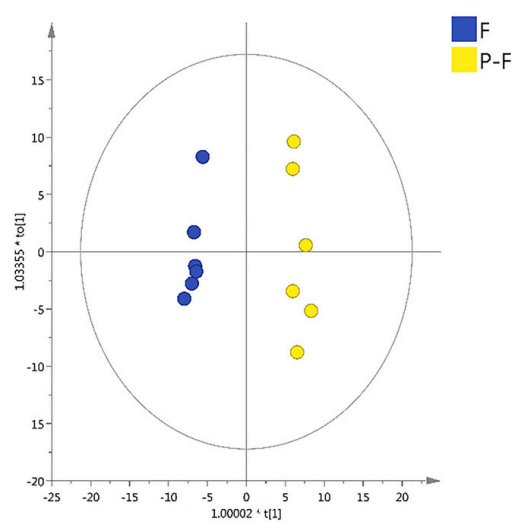

D

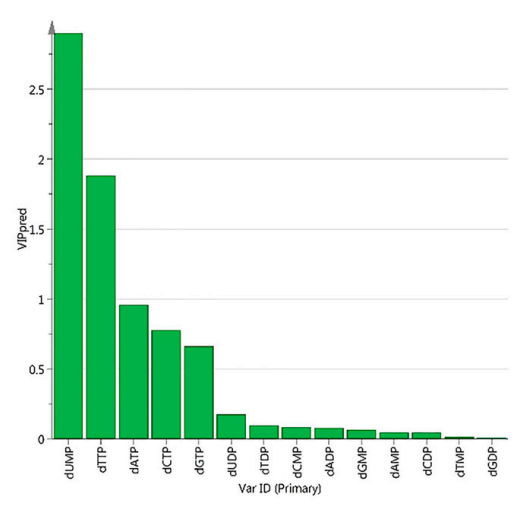

F

Figure 2. Score plots of PCA models comprising: (A) (RNs pool sizes, $\mathrm{R}_{2} \mathrm{X}=0.998, \mathrm{Q}^{2}=0.993$ ); and (B) (dRNs pool sizes, $\mathrm{R}_{2} \mathrm{X}=0.978, \mathrm{Q}^{2}=0.915$ ). Score plots of OPLS-DA models comprising: (C) (RNs pool sizes, $R_{2} X=0.995, R_{2} Y=0.984, Q^{2}=0.954$ ); and (D) (dRNs pool sizes, $R_{2} X=0.987$, $R_{2} \mathrm{Y}=0.985, \mathrm{Q}^{2}=0.965$ ). VIP plots of: (E) RNs pool sizes; and (F) dRNs pool sizes (N: Normal control group; F: 5-FU-treated group; P: PHA-treated group; P-F: combination group). 


\subsection{Effect of PHA Extract Incubation on RNs and dRNs Pool Sizes}

When HepG2 cells were exposed to the PHA extract alone, there were no remarkably changes in the levels of the RNs, except for the slight decrease in ATP, GTP, guanosine monophosphate (GMP) and the little increase in cytidine diphosphate (CDP). The effects of 5-FU on RNs and dRNs pool sizes in cells upon exposure to 5-FU for different durations have already been reported in our previous paper [24]. The levels of four nucleoside triphosphates exhibited similar increases after treatment of 5-FU with or without PHA extract (Figure 3 and Table 2). The effects of 5-FU on ribonucleotide triphosphates were possibly related to its cytostatic effect. However, it was interesting that ATP, CTP, GTP and UTP levels in the combination group significantly decreased compared with the 5-FU alone group. Meanwhile, there were significantly increases in adenosine monophosphate (AMP), cytidine monophosphate (CMP) and GMP levels after combined use with PHA extract. Nucleoside monophosphate kinase (NMPK) can phosphorylate monophosphate metabolites into diphosphates, which could be transformed to triphosphates metabolites by nucleoside diphosphate kinase (NDPK) [3]. Given that there was no effect of PHA extract on the level of nucleoside diphosphates, the nucleoside monophosphates and nucleoside triphosphates could have been affected by PHA. It was revealed that NMPK and NDPK may be the target for PHA, but this needs to be further studied.
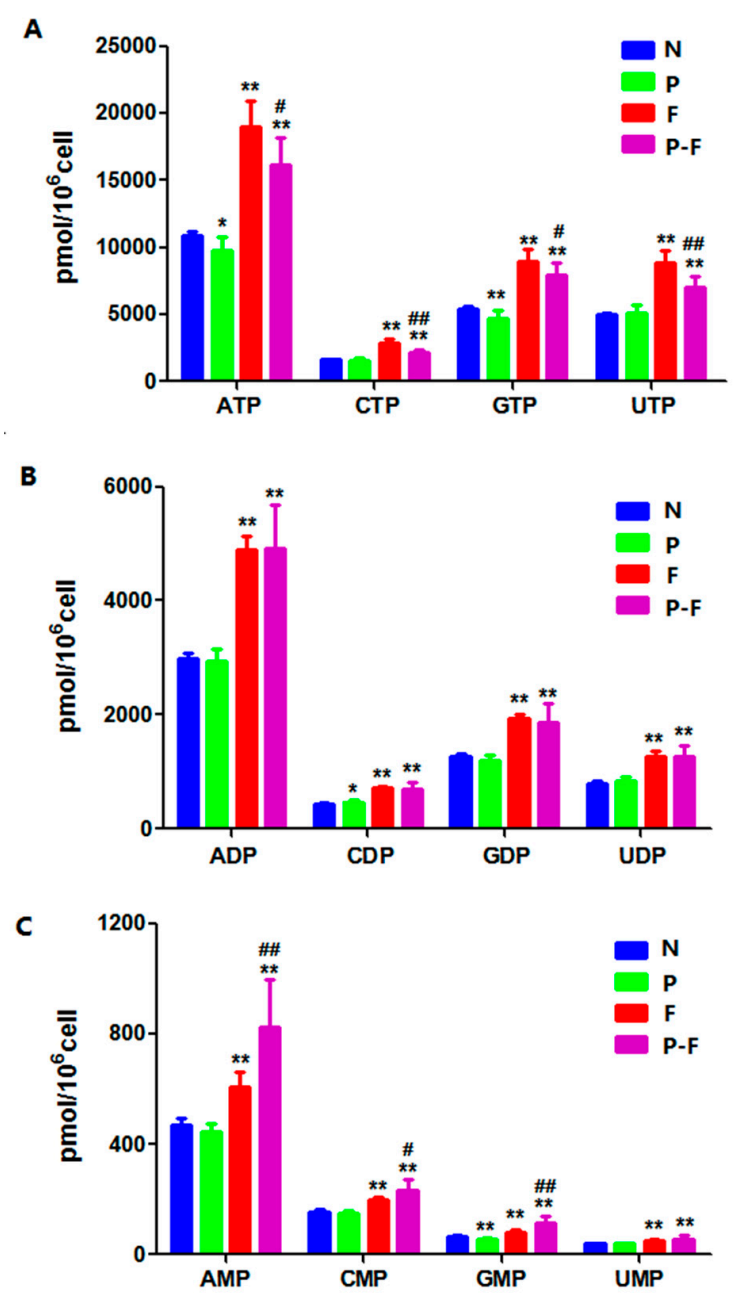

Figure 3. Levels of ribonucleotides in HepG2 cells after treatment with drugs for $24 \mathrm{~h}$ : (A) nucleoside triphosphate levels in every group; (B) nucleoside diphosphate levels in every group; and $(\mathbf{C})$ nucleoside monophosphate levels in every group. Each group of data are represented as mean \pm SD of three independent experiments. ${ }^{*} p<0.05$ and ${ }^{* *} p<0.01$, compared with the control group; ${ }^{\#}<0.05$ and ${ }^{\# \#} p<0.01$, compared with the 5-FU group. 
Table 2. Levels of RNs in HepG2 cells of every group (pmol/106 cell).

\begin{tabular}{|c|c|c|c|c|c|}
\hline & MRM Transition & Control & $\mathbf{F}$ & $\mathbf{P}$ & P-F \\
\hline ATP & $506.0 \rightarrow 159.0$ & $10904.7 \pm 275.1$ & $18975.6 \pm 1728.7^{* *}$ & $9775.0 \pm 936.9^{*}$ & $16173.0 \pm 1784.1^{* *, \#}$ \\
\hline $\mathrm{ADP}$ & $426.0 \rightarrow 328.0$ & $2985.5 \pm 89.5$ & $49033 \pm 207.5^{* *}$ & $2933.1 \pm 190.5$ & $4916.2 \pm 709.2^{* *}$ \\
\hline AMP & $346.0 \rightarrow 79.3$ & $469.5 \pm 21.1$ & $608.5 \pm 49.7^{* *}$ & $444.1 \pm 27.6$ & $823.9 \pm 156.21 * *, \# \#$ \\
\hline CTP & $482.0 \rightarrow 384.0$ & $1601.3 \pm 41.7$ & $2860.0 \pm 269.9^{* *}$ & $1523.9 \pm 162.1$ & $2116.5 \pm 213.2^{* *, \# \#}$ \\
\hline CDP & $402.0 \rightarrow 159.0$ & $430.3 \pm 15.9$ & $707.9 \pm 35.9 * *$ & $468.4 \pm 28.9 *$ & $697.7 \pm 98.7^{* *}$ \\
\hline CMP & $322.0 \rightarrow 79.4$ & $153.4 \pm 7.01$ & $200.2 \pm 7.2^{* *}$ & $148.3 \pm 8.6$ & $232.2 \pm 37.0^{* * \#}$ \\
\hline GTP & $522.0 \rightarrow 423.9$ & $5428.2 \pm 110.7$ & $8923.2 \pm 807.2 * *$ & $4668.0 \pm 547.8^{* *}$ & $7912.1 \pm 807.8^{* *, \#}$ \\
\hline GDP & $442.0 \rightarrow 344.0$ & $1263.4 \pm 45.3$ & $1935.3 \pm 64.0^{* *}$ & $1203.3 \pm 87.2$ & $1858.9 \pm 305.0^{* *}$ \\
\hline GMP & $362.0 \rightarrow 79.30$ & $67.0 \pm 2.8$ & $81.3 \pm 8.2^{* *}$ & $55.0 \pm 4.1^{* *}$ & 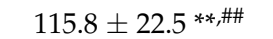 \\
\hline UTP & $482.9 \rightarrow 385.0$ & $4989.0 \pm 114.2$ & $8858.3 \pm 774.9^{* *}$ & $5097.9 \pm 517.1$ & $7045.6 \pm 741.2 * *$ \\
\hline UDP & $403.0 \rightarrow 159.0$ & $792.9 \pm 38.2$ & $1280.0 \pm 69.9^{* *}$ & $844.9 \pm 55.7$ & $1261.1 \pm 189.2 * *$ \\
\hline UMP & $323.0 \rightarrow 79.3$ & $39.3 \pm 1.8$ & $49.0 \pm 4.2 * *$ & $38.6 \pm 2.3$ & $56.4 \pm 12.4^{* *}$ \\
\hline
\end{tabular}

Table 3 summarizes the levels of dRNs in each group. As far as we know, the accumulation of dUMP pools and the depletion of dTTP pools is the key mechanism of action of 5-FU via the inhibition of thymidylate synthase (TS) [25]. Furthermore, the level of dUMP in the 5-FU combined with PHA group was significantly higher than that of 5-FU group, while the dTTP pools reduced significantly (Figure 4). These findings suggested that PHA extract may enhance the effect of 5-FU through regulation of RNs and dRNs pool sizes. TS protein level was evaluated by Western blotting of HepG2 cell line. HepG2 cells were incubated for $24 \mathrm{~h}$ with $50.0 \mu \mathrm{M}$ 5-FU alone, $50.0 \mu \mathrm{g} / \mathrm{mL}$ PHA alone and the combination of these two drugs, respectively. As shown in Figure 5A, the level of TS protein remained unchanged after exposure to PHA extract. Expectedly, treatment with 5-FU induced the formation of two distinct bands of TS, one at $35 \mathrm{kDa}$ and the other one at $38 \mathrm{kDa}$ approximately. The lane at $35 \mathrm{kDa}$ represents the normal TS. The second bands of TS with higher molecular mass represent the conjugation, which is formed by FdUMP, TS and CH2-THF (5, 10-methylene-tetrahydrofolate) [26]. However, there was no inhibitory effect on this enzyme after combined use with PHA extract. Since deoxycytidine triphosphate (dCMP) is a precursor of dUMP [27], the increase of dUMP in combination group could be caused by increase of dCMP. These possibilities are under investigation.

Table 3. Levels of dRNs in HepG2 cells of every group (pmol/10 $10^{6}$ cell).

\begin{tabular}{|c|c|c|c|c|c|}
\hline & MRM Transition & Control & F & $\mathbf{P}$ & P-F \\
\hline dATP & $490.0 \rightarrow 159.1$ & $30.34 \pm 0.5$ & $113.11 \pm 10.2 * *$ & $32.45 \pm 1.8^{*}$ & $126.9 \pm 16.4^{* *}$ \\
\hline dADP & $410.0 \rightarrow 79.0$ & $0.0568 \pm 0.005$ & $0.2789 \pm 0.02 * *$ & $0.0526 \pm 0.003$ & $0.3414 \pm 0.05^{* *, \#}$ \\
\hline dAMP & $330.0 \rightarrow 79.0$ & $0.0068 \pm 0.002$ & $0.0354 \pm 0.003 * *$ & $0.007 \pm 0.001$ & $0.0525 \pm 0.01^{* *}, \# \#$ \\
\hline $\mathrm{dCTP}$ & $465.9 \rightarrow 159.0$ & $28.48 \pm 0.6$ & $138.3 \pm 12.3^{* *}$ & $24.00 \pm 1.8^{* *}$ & $126.6 \pm 18.8^{* *}$ \\
\hline $\mathrm{dCDP}$ & $386.0 \rightarrow 79.0$ & $0.0297 \pm 0.005$ & $0.1185 \pm 0.01 * *$ & $0.0189 \pm 0.002 * *$ & $0.1446 \pm 0.03^{* *}$ \\
\hline $\mathrm{dCMP}$ & $306.0 \rightarrow 79.0$ & $0.0499 \pm 0.006$ & $0.0394 \pm 0.007$ * & $0.0304 \pm 0.008^{* *}$ & $0.0923 \pm 0.016^{* *, \# \#}$ \\
\hline dGTP & $581.0 \rightarrow 152.1$ & $40.35 \pm 2.3$ & $12.81 \pm 0.50^{* *}$ & $34.22 \pm 3.4^{* *}$ & 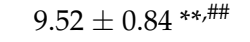 \\
\hline dGDP & $501.0 \rightarrow 152.0$ & $2.12 \pm 0.09$ & $0.13 \pm 0.07^{* *}$ & $2.22 \pm 0.4$ & $0.13 \pm 0.06^{* *}$ \\
\hline dGMP & $421.0 \rightarrow 152.0$ & $2.92 \pm 0.1$ & $0.28 \pm 0.07^{* *}$ & $2.72 \pm 0.4$ & $0.35 \pm 0.09 * *$ \\
\hline dUTP & $467.0 \rightarrow 159.0$ & *UDL & ${ }^{*} \mathrm{UDL}$ & *UDL & ${ }^{*} \mathrm{UDL}$ \\
\hline dUDP & $387.0 \rightarrow 79.0$ & $0.02 \pm 0.01$ & $0.22 \pm 0.07^{* *}$ & $1.52 \pm 3.4$ & $0.59 \pm 0.39^{* *, \#}$ \\
\hline dUMP & $307.0 \rightarrow 79.0$ & $0.17 \pm 0.03$ & $76.38 \pm 5.7^{* *}$ & $0.15 \pm 0.05$ & 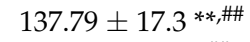 \\
\hline dTTP & $481.0 \rightarrow 159.1$ & $85.54 \pm 1.0$ & $40.61 \pm 3.0^{* *}$ & $92.77 \pm 7.2 *$ & 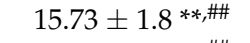 \\
\hline dTDP & $401.0 \rightarrow 79.0$ & $2.66 \pm 0.2$ & $1.25 \pm 0.05^{* *}$ & $3.11 \pm 0.1 * *$ & $1.14 \pm 0.07^{* *, \# \#}$ \\
\hline dTMP & $321.0 \rightarrow 79.0$ & $0.0435 \pm 0.005$ & $0.004 \pm 0.0008^{* *}$ & $0.049 \pm 0.003 *$ & $0.0071 \pm 0.004^{* *}$ \\
\hline
\end{tabular}

Note: All data were expressed as mean \pm SD values by three independent experiments. $P$ value of less than $0.05\left({ }^{*} p<0.05,{ }^{* *} p<0.01\right.$, versus the control group; ${ }^{\#} p<0.05$, ${ }^{\# \#} p<0.01$, compared with the 5-FU group) are considered significant; *UDL, under detected limit of assay. 


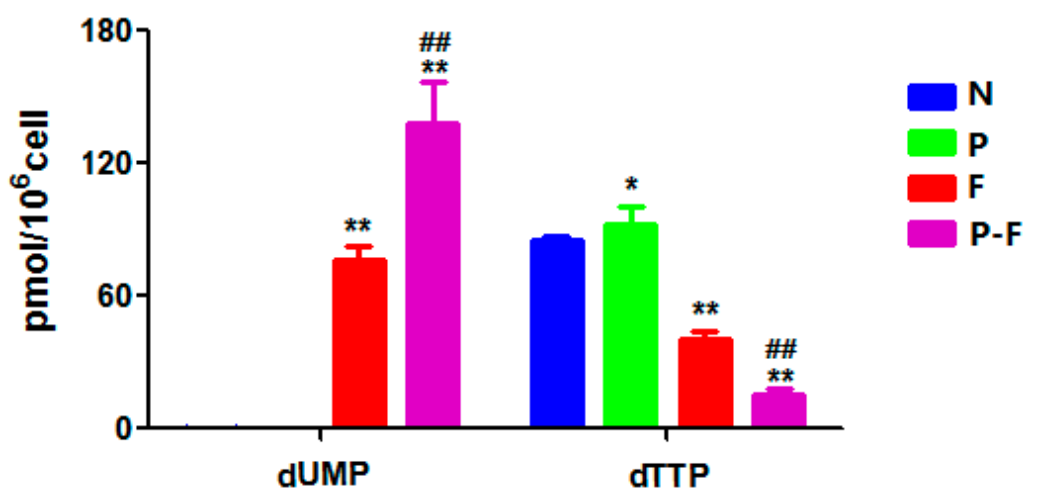

Figure 4. Levels of dUMP and dTTP after PHA and 5-FU treatments. Each group of data are represented as mean \pm SD of three independent experiments. ${ }^{*} p<0.05$ and ${ }^{* *} p<0.01$, compared with the control group; ${ }^{\# \#} p<0.01$, compared with the 5-FU group.

A

TS

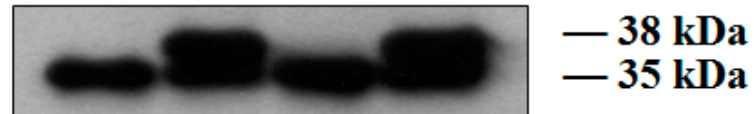

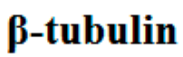

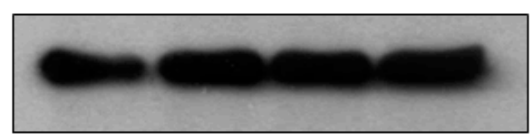

5-FU $(\boldsymbol{\mu M}) \quad-\quad 50.0 \quad-\quad 50.0$

P.amarus $(\mu \mathrm{g} / \mathrm{mL}) \quad-\quad-\quad 50.0 \quad 50.0$

B

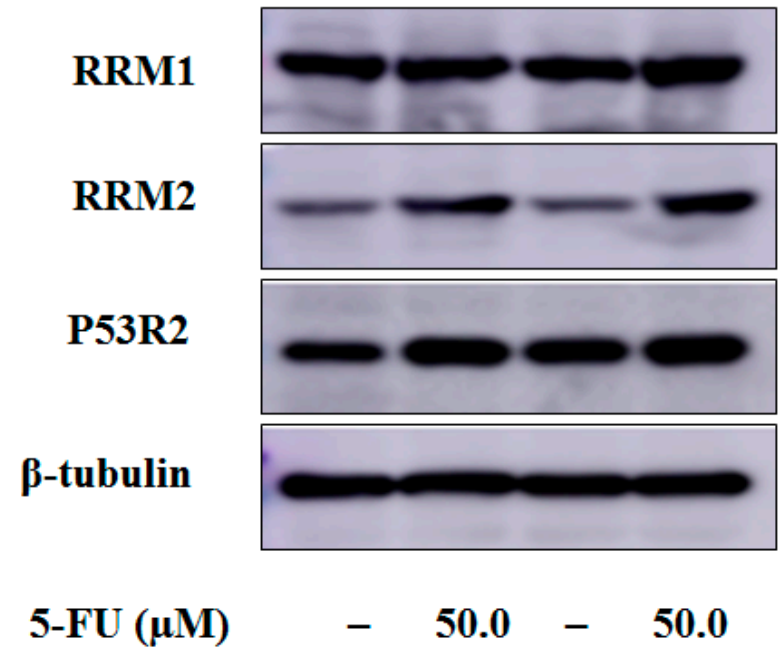

Figure 5. Western blot analysis in HepG2 cells: (A) expression of TS; and (B) expression of ribonucleotide reductase subunits M1 (RRM1) and M2 (RRM2), P53-controlled ribonucleotide reductase $(\mathrm{P} 53 \mathrm{R} 2)$.

\subsection{PHA extract Induced Cell Cycle Arrest in HepG2 Cells}

After exposure to 5-FU $(50.0 \mu \mathrm{M}), \operatorname{PHA}(50.0 \mu \mathrm{g} / \mathrm{mL})$ or combination for $24 \mathrm{~h}$, cell cycle arrest in HepG2 cells was investigated using flow cytometry. Results showed that treatment for $24 \mathrm{~h}$ with PHA extract alone induced the cells arrest in G2/M phase slightly. However, there were no significant differences in other phases (Figure 6). At the same time, 5-FU group showed a remarkable inhibition in 
the G0/G1 and S phases by a decreased distribution in the G2/M phase. Compared with 5-FU group, combined treatment with 5-FU and PHA extract induced a higher proportion arrest in $\mathrm{S}$ phase and decreased distribution in G0/G1 phase in HepG2 cells. This suggested that PHA extract could increase the role of cell cycle arrest at $\mathrm{S}$ phase induced by $5-\mathrm{FU}$ in HepG2 cells.
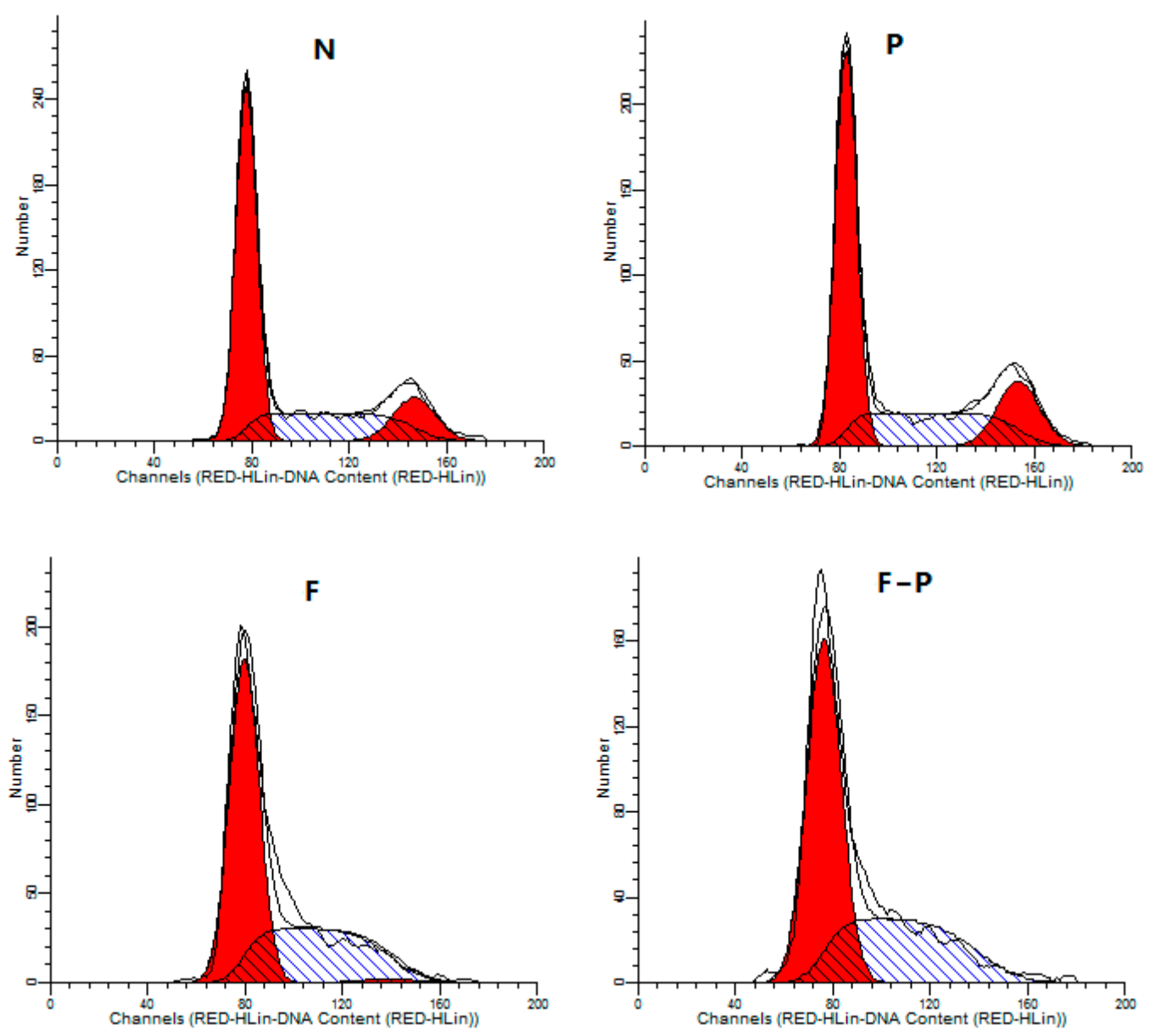

Figure 6. Cell cycle effects of 5-FU and PHA in HepG2 cells after $24 \mathrm{~h}$ exposure.

Human ribonucleotide reductase (RR) is composed of three known subunits, RRM1 (large subunit), RRM2 (small subunit), and encoded P53-controlled ribonucleotide reductase (P53R2), which are differentially regulated during the cell cycle. R1 protein concentration is relatively constant throughout the cell cycle. M2 protein is low outside $S$ phase $[28,29]$. Compared with the control group, the expression of RRM2 was increased after 5-FU treatment with or without PHA extract, which was caused by cell cycle arrest at $S$ phase (Figure 5B). Thus high levels of deoxyadenosine diphosphate (dADP), deoxycytidine diphosphate (dCDP), deoxyadenosine triphosphate (dATP) and deoxycytidine triphosphate (dCTP) were associated with high level of RRM2. As already noted, dTTP stimulates the formation of deoxyguanosine diphosphate (dGDP) and hence of deoxyguanosine triphosphate (dGTP). The subsequent decrease in the levels of dGDP and dGTP in F and P-F groups may be, at least in part, caused by decrease of dTTP due to inhibition of 5-FU on TS.

\section{Materials and Methods}

\subsection{Materials}

LC-MS grade methanol, acetonitrile and acetic acid were purchased from Anaqua Chemical Supply Co., Houston, TX, USA. Hexylamine (HA), diethylamine (DEA), trioctylamine, 
1,1,2-trichlorotrifluoroethane, stable isotope labeled adenosine- ${ }^{13} \mathrm{C}_{10}{ }^{15} \mathrm{~N}_{5}$-triphosphate $\left(\operatorname{ATP}^{13} \mathrm{C}^{15} \mathrm{~N}\right)$, dimethyl sulfoxide (DMSO), trypsin-EDTA solution and 3-[(4,5)-dimethylthiazol-2-yl]-2,5-diphenyl tetrazolium bromide (MTT) were purchased from Sigma Aldrich Chemical Co., St. Louis, MO, USA. Ultra-pure water was obtained from a Milli-Q Gradient Water System (Millipore Corp., Bedford, MA, USA). For culturing cells, phosphate buffered saline, $\mathrm{pH}=7.8$ (PBS), Dulbecco's Modified Eagle Medium (DMEM), penicillin-streptomycin solution and fetal bovine serum (FBS) were obtained from Gibco Invitrogen Corp., Carlsbad, CA, USA. Human hepatocellular cancer HepG2 cell line was supplied by American Type Culture Collection (ATCC), Rockville, MD, USA.

\subsection{Preparation of PHA Extract}

PHA was collected from the Hepu town of Beihai, Guangxi province, China and identified by Professor Buming Liu at the Guangxi Key Laboratory of Traditional Chinese Medicine Quality Standards, China. The dried powder of PHA (about $5 \mathrm{~g}$ ) was accurately weighed into a $250 \mathrm{~mL}$ flask and immersed in $100 \mathrm{~mL}$ of $75 \%$ ethanol $(v / v)$ overnight. The mixture was ultrasonically extracted at room temperature for $1 \mathrm{~h}$ before the extract was filtered. The filtrate was condensed by a rotary evaporator followed with vacuum drying at $60^{\circ} \mathrm{C}$. A total of 59 compounds were identified and tentatively assigned structures for the establishment of fingerprint by previously published method [23]. By comparing the retention time and MS data with those of reference compounds, the contents of protocatechuic acid, corilagin, caffeic acid, ellagic acid, rutin, quercetin, luteolin, qaempferol, phyllanthin, niranthin, oleanolic acid, palmitic acid in the PHA were 3.91, 295.2, 15.2, $574.2,217.7,92.3,0.10,0.20,792.3,260.98,16.3$ and $12.9 \mu \mathrm{g} / \mathrm{g}$, respectively.

\subsection{LC/MS/MS Assay}

This was performed on a Thermo Fisher TSQ LC-MS/MS system consisted of an Accela Autosampler, an Accela pump and a Quantum Access triple quadrupole mass spectrometer (Thermo Fisher Scientific Co., San Jose, CA, USA). Data acquisition was performed with the Xcalibur software version 2.0.7, and data processing using the Thermo LCquan 2.5.6 data analysis program (Thermo Fisher). The chromatographic separation was achieved using an XTerra-MS C18 column $(150 \mathrm{~mm} \times 2.1 \mathrm{~mm}$ i.d., $3.5 \mu \mathrm{m}$, Waters Corp., Milford, MA, USA). The two eluents were: (A) $5 \mathrm{mM}$ HA- $-5 \%$ DEA in water, $\mathrm{pH}$ adjusted to 10 with acetic acid; and (B) $50 \%$ acetonitrile in water. The mobile phase consisted of a linear gradient of $A$ and B: $0-15 \mathrm{~min}, 100 \%-80 \% \mathrm{~A}(v / v) ; 15-35 \mathrm{~min}$, 80\%-70\% A; 35-45 min, 70\%-45\% A; 45-46 min, 45\%-0\% A; $46-50 \mathrm{~min}, 0 \%-0 \%$ A; $50-51 \mathrm{~min}, 0 \%-100 \%$ A; 51-70 min, $100-100 \%$ A. The liquid flow-rate was set at $0.3 \mathrm{~mL} / \mathrm{min}$, and the column temperature was maintained at $35^{\circ} \mathrm{C}$. For all dRNs, the following optimized parameters were obtained. The sheath gas pressure reached $40 \mathrm{psi}$. The ion spray voltage was set at $3000 \mathrm{~V}$ for negative mode and $4000 \mathrm{~V}$ for positive mode at a temperature of $350{ }^{\circ} \mathrm{C}$ and auxiliary gas pressure of $15 \mathrm{psi}$. Quantification was performed using multiple reactions monitoring (MRM) as previously published [24].

\subsection{Cell Culture}

HepG2 cells were cultured in DMEM medium supplemented with $10 \%$ fetal bovine serum (FBS), 100 units $/ \mathrm{mL}$ penicillin, $100 \mu \mathrm{g} / \mathrm{mL}$ streptomycin in a $37^{\circ} \mathrm{C}$ humidified incubator with a $5 \% \mathrm{CO}_{2}$ atmosphere. HepG2 cells were seeded in $100 \mathrm{~mm}$ by $20 \mathrm{~mm}$ dishes (Corning Inc., Corning, NY, USA). After overnight culture, cells were divided into different groups as follows: control group $(\mathrm{N})$, cells was incubated with medium alone; 5-FU group (F), cells were exposed to $50.0 \mu \mathrm{M}$ of 5-FU for $24 \mathrm{~h}$; PHA group (P), cells were exposed to $50.0 \mu \mathrm{g} / \mathrm{mL}$ of PHA extraction for $24 \mathrm{~h}$; and combination group (P-F), cells were exposed to $50.0 \mu \mathrm{M}$ of 5-FU combined with $50.0 \mu \mathrm{g} / \mathrm{mL}$ of PHA extraction for $24 \mathrm{~h}$. An extra dish of cells was incubated for cell counting on the day of cell harvest for normalization of nucleotide pools, and the viability assessed by tryphan blue exclusion assay. 


\subsection{Preparation of Cell Pellets}

Monolayer HepG2 cells were washed with ice-cold PBS once and were trypsinized with $0.25 \%$ trypsin-EDTA. Cells from two or three dishes were then re-suspended with $12 \mathrm{~mL}$ ice-cold PBS. After centrifugation at $1000 \mathrm{rpm}$ for $5 \mathrm{~min}$, the cell pellet was washed with $1 \mathrm{~mL}$ ice-cold PBS again and spun down at $1000 \mathrm{rpm}$ for $5 \mathrm{~min}$. The cell pellet was incubated with $150 \mu \mathrm{L}$ of $15 \%$ trichloroacetic acid (TCA) containing $7.5 \mu \mathrm{L}$ of $20.0 \mu \mathrm{M} \mathrm{ATP}{ }^{13} \mathrm{C}^{15} \mathrm{~N}$ as internal standard and placed on ice for $10 \mathrm{~min}$. After centrifugation at 13,500 rpm for $15 \mathrm{~min}$ in the cold room, the acidic supernatant was separated and neutralized twice with $80 \mu \mathrm{L}$ mixture of trioctylamine and 1,1,2-trichlorotrifluoroethane (45:55 $\mathrm{v} / \mathrm{v})$. Samples were stored at $-80^{\circ} \mathrm{C}$ until analysis within two days.

\subsection{MTT Assay}

The inhibitory effect of different groups on HepG2 cells was determined by the cytotoxic MTT assay. HepG2 cells were seeded in 96 wells plate (LabServ, Thermo Fisher Scientific Co., Beijing, China) at $1 \times 10^{4}$ cells/well. After incubation, they were treated with indicated concentrations of 5-FU, PHA or combination for 24, 48 and $72 \mathrm{~h}$. MTT solution (final concentration of $0.5 \mathrm{mg} / \mathrm{mL}$ in medium) was added to each well and incubated further for $4 \mathrm{~h}$. The medium was removed, and $100 \mu \mathrm{L}$ of DMSO was added to each well to dissolve the purple crystals of formazan. Absorbance was measured at $570 \mathrm{~nm}$ with a microplate UV/VIS spectrophotometer (Infinite M200 PRO, Tecan Austria GmbH 5082, Grödig, Austria); reference wavelength was $650 \mathrm{~nm}$. The cell number was determined using a hemocytometer. $\mathrm{IC}_{50}$ (half maximal (50\%) inhibitory concentration) values of 5-FU were calculated by GraphPad Prism software (GraphPad Software, Inc., San Diego, CA, USA). Cell viability $(\%)=(\mathrm{OD}$ (treated $)-\mathrm{OD}($ blank $)) /(\mathrm{OD}($ control, untreated $)-\mathrm{OD}($ blank $)) \times 100$. Drug interaction was evaluated by the combination index (CI) methods, whereas $\mathrm{CI}<1, \mathrm{CI}=1$, or $\mathrm{CI}>1$ indicates synergism, additive effect or antagonism, respectively [30,31]. CI values were calculated by CompuSyn software (ComboSyn, Inc., Paramus, NJ, USA).

\subsection{Cell Cycle Analysis}

The cell cycle analysis was determined as previously described [32]. In brief, cells were seeded at $4.5 \times 10^{5}$ cells/well in 6-well culture plates in duplicate, and incubated with indicated concentrations of 5-FU, PHA extract or combination for $24 \mathrm{~h}$. They were then harvested and fixed in $70 \%(\mathrm{v} / \mathrm{v})$ cold ethanol overnight at $4{ }^{\circ} \mathrm{C}$. The fixed cells were collected by centrifugation and re-suspended in PBS and incubated with $5 \mathrm{mg} / \mathrm{mL}$ propidium iodide (Sigma-Aldrich Co.) and $10 \mathrm{mg} / \mathrm{mL}$ RNase A (Sigma-Aldrich) at room temperature for $30 \mathrm{~min}$ in the dark. The cells were then analyzed on a flow cytometer (Muse ${ }^{\mathrm{TM}}$ cell analyzer, Merck Millipore, Darmstadt, Germany). Finally, the percentages of cells in different phases (G0/G1, S and G2/M) were calculated using Modfit software (Verity Software House, Verity Software House, Topsham, ME, USA).

\subsection{Western Blot Analysis}

The cells were treated with 5-FU, PHA extract and the combination of them for $24 \mathrm{~h}$, respectively. At the end of the incubation time, every group cells were harvested and lysed in RIPA buffer (Cell Signaling Technologies Inc., Beverly, MA, USA). Bradford reagent (Bio-Rad Laboratory, Hercules, CA, USA) was used to determine protein concentration. Then, the cell lysates were mixed with $5 \times$ SDS-loading buffer $(4: 1, v / v)$ and heated at $100{ }^{\circ} \mathrm{C}$ with locked capping for $5 \mathrm{~min}$. The cell lysates $(40 \mu \mathrm{g})$ were subjected to $10 \%$ SDS-PAGE. After electrophoresis, the cell extracts from SDS-PAGE were transferred to nitrocellulose membrane (Millipore Co.). Then, the membranes were incubated with rabbit RRM1 (D12F12) antibody (Dilution ratio = 1:1000; Cell Signaling Technology, Inc.), RRM2 [EPR11820] antibody (Dilution ratio = 1:1000; abcam $^{\circledR}$, Cambridge, UK), p53R2 [EPR8816] antibody (Dilution ratio $=1: 1000 ;$ abcam $^{\circledR}$ ), thymidylate synthase (D5B3) antibody (Dilution ratio = 1:1000; Cell Signaling Technology, Inc.) and $\beta$-tubulin antibody (Dilution ratio = 1:2000; Santa Cruz Biotechnology, 
CA, USA) overnight at $4{ }^{\circ} \mathrm{C}$. Furthermore, the membranes were incubated with HRP-conjugated antibodies (Dilution ratio = 1:5000; Cell Signaling Technology, Inc.) for one hour. Visualization of the protein bands by using the enhanced chemiluminescence reagents (Invitrogen, Paisley, Scotland, UK). The bands analyzed by using the Image J 1.46r software (National Institutes of Health, Bethesda, MD, USA).

\section{Conclusions}

In this study, the interaction of combined use of PHA and 5-FU $(50.0 \mu \mathrm{M})$ on cell growth and cell cycle progression were investigated. Although PHA alone has no significant impact on the levels of RNs and dRNs, combined use of 5-FU with PHA enhanced cytotoxic activity through regulation of ribonucleotides and deoxyribonucleotides pool sizes which might be due to the cell cycle arrest or regulation of key enzyme steps in intracellular RNs and dRNs metabolism. Combined pharmacotherapy is a popular strategy that would enhance the anti-cancer activities of cytotoxic drugs while reducing cancer cells' chemo-resistance. The use of PHA for the treatment of liver diseases has a long history in several countries. TS and RR represent two critical targets in cancer chemotherapy. Although PHA has no direct effect on TS and RR, it could perturb the levels of RNs and dRNs and could induce cell cycle arrest when combined with 5-FU. Thus, interaction between PHA and 5-FU could occur and may lead to serious side effect because imbalances in the four dNTPs pools have genotoxic consequences.

Acknowledgments: This work was supported by Macao Science and Technology Development Fund (FDCT), Project No. 006/2015/A1 and open Project of Guangxi Key Laboratory of Traditional Chinese Medicine Quality Standards (No. Guizhongzhongkai201501).

Author Contributions: W. Zhang, F.G. Xu and B.M. Liu conceived and designed the experiments, analyzed the data and revised the manuscript. J.R. Guo, C.Y. Wang and Q.Q. Chen performed the experiments and drafted the manuscript. C.W.K. Lam reviewed the data and revised the manuscript.

Conflicts of Interest: The authors declare no conflict of interest.

\section{References}

1. Jordheim, L.P.; Durantel, D.; Zoulim, F.; Dumontet, C. Advances in the development of nucleoside and nucleotide analogs for cancer and viral diseases. Nat. Rev. Drug Discov. 2013, 12, 447-464. [CrossRef] [PubMed]

2. Krupp, G. Enzymatic RNA synthesis and RNase P. Evolutionary aspects. Mol. Biol. Rep. 1995, 22, 177-180. [CrossRef] [PubMed]

3. Van Rompay, A.R.; Johansson, M.; Karlsson, A. Phosphorylation of nucleosides and nucleoside analogs by mammalian nucleoside monophosphate kinases. Pharmacol. Ther. 2000, 87, 189-198. [CrossRef]

4. Houghton, J.A.; Tillman, D.M.; Harwood, F.G. Ratio of 2'-deoxyadenosine-5'-triphosphate/thymidine-5'triphosphate influences the commitment of human colon carcinoma cells to thymineless death. Clin. Cancer Res. 1995, 1, 723-730. [PubMed]

5. Mitrovski, B.; Pressacco, J.; Mandelbaum, S.; Erlichman, C. Biochemical effects of folate-based inhibitors of thymidylate synthase in MGH-U1 cells. Cancer Chemother. Pharmacol. 1994, 35, 109-114. [CrossRef] [PubMed]

6. Marsoni, S. Efficacy of adjuvant fluorouracil and folinic acid in colon cancer. International Multicentre Pooled Analysis of Colon Cancer Trials (IMPACT) investigators. Lancet 1995, 345, 939-944.

7. Douillard, J.Y.; Cunningham, D.; Roth, A.D.; Navarro, M.; James, R.D.; Karasek, P.; Jandik, P.; Iveson, T.; Carmichael, J.; Alakl, M.; et al. Irinotecan combined with fluorouracil compared with fluorouracil alone as first-line treatment for metastatic colorectal cancer: A multicentre randomised trial. Lancet 2000, 355, 1041-1047. [CrossRef]

8. Johnston, P.G.; Kaye, S. Capecitabine: A novel agent for the treatment of solid tumors. Anticancer Drugs 2001, 12, 639-646. [CrossRef] [PubMed]

9. Longley, D.B.; Harkin, D.P.; Johnston, P.G. 5-Fluorouracil: Mechanisms of action and clinical strategies. Nat. Rev. Cancer 2003, 3, 330-338. [CrossRef] [PubMed] 
10. Miura, K.; Kinouchi, M.; Ishida, K.; Fujibuchi, W.; Naitoh, T.; Ogawa, H.; Ando, T.; Yazaki, N.; Watanabe, K.; Haneda, S.; et al. 5-Fu metabolism in cancer and orally-administrable 5-fu drugs. Cancers (Basel) 2010, 2, 1717-1730. [CrossRef] [PubMed]

11. Qi, F.H.; Li, A.Y.; Inagaki, Y.; Gao, J.J.; Li, J.J.; Kokudo, N.; Li, X.K.; Tang, W. Chinese herbal medicines as adjuvant treatment during chemo- or radio-therapy for cancer. Biosci. Trends 2010, 4, 297-307. [PubMed]

12. Konkimalla, V.B.; Efferth, T. Evidence-based Chinese medicine for cancer therapy. J. Ethnopharmacol. 2008, 116, 207-210. [CrossRef] [PubMed]

13. Roengrit, T.; Wannanon, P.; Prasertsri, P.; Kanpetta, Y.; Sripanidkulchai, B.O.; Wattanathorn, J.; Leelayuwat, N. Antioxidant effect of Phyllanthus amarus after moderate-intensity exercise in sedentary males: A randomized crossover (double-blind) study. J. Phys. Ther. Sci. 2015, 27, 1181-1186. [CrossRef] [PubMed]

14. Calixto, J.B.; Santos, A.R.; Cechinel Filho, V.; Yunes, R.A. A review of the plants of the genus Phyllanthus: Their chemistry, pharmacology, and therapeutic potential. Med. Res. Rev. 1998, 18, 225-258. [CrossRef]

15. Patel, J.R.; Tripathi, P.; Sharma, V.; Chauhan, N.S.; Dixit, V.K. Phyllanthus amarus: Ethnomedicinal uses, phytochemistry and pharmacology: A review. J. Ethnopharmacol. 2011, 138, 286-313. [CrossRef] [PubMed]

16. Tang, Y.Q.; Jaganath, I.B.; Sekaran, S.D. Phyllanthus spp. induces selective growth inhibition of PC-3 and MeWo human cancer cells through modulation of cell cycle and induction of apoptosis. PLoS ONE 2010, 5, e12644. [CrossRef] [PubMed]

17. Islam, A.; Selvan, T.; Mazumder, U.; Gupta, M.; Ghosal, S. Antitumour effect of phyllanthin and hypophyllanthin from Phyllanthus amarus against Ehrlich ascites carcinoma in mice. Pharmacologyonline 2008, 2, 796-807.

18. Blumberg, B.S.; Millman, I.; Venkateswaran, P.S.; Thyagarajan, S.P. Hepatitis B virus and primary hepatocellular carcinoma: Treatment of HBV carriers with Phyllanthus amarus. Vaccine 1990, 8, S86-S92. [CrossRef]

19. Ott, M.; Thyagarajan, S.P.; Gupta, S. Phyllanthus amarus suppresses hepatitis B virus by interrupting interactions between HBV enhancer I and cellular transcription factors. Eur. J. Clin. Investig. 1997, 27, 908-915. [CrossRef]

20. Rajeshkumar, N.V.; Joy, K.L.; Kuttan, G.; Ramsewak, R.S.; Nair, M.G.; Kuttan, R. Antitumour and anticarcinogenic activity of Phyllanthus amarus extract. J. Ethnopharmacol. 2002, 81, 17-22. [CrossRef]

21. Taesotikul, T.; Dumrongsakulchai, W.; Wattanachai, N.; Navinpipat, V.; Somanabandhu, A.; Tassaneeyakul, W. Inhibitory effects of Phyllanthus amarus and its major lignans on human microsomal cytochrome P450 activities: Evidence for CYP3A4 mechanism-based inhibition. Drug Metab. Pharmacokinet. 2011, 26, 154-161. [CrossRef] [PubMed]

22. Colombo, R.; De L, B.; Andrea, N.; Teles, H.L.; Silva, G.H.; Bomfim, G.C.; Burgos, R.C.; Cavalheiro, A.J.; Da Silva Bolzani, V.; Silva, D.H.S. Validated HPLC method for the standardization of Phyllanthus niruri (herb and commercial extracts) using corilagin as a phytochemical marker. Biomedical. Chromatogr. 2009, 23, 573-580. [CrossRef] [PubMed]

23. Guo, J.; Chen, Q.; Wang, C.; Qiu, H.; Liu, B.; Jiang, Z.H.; Zhang, W. Comparison of two exploratory data analysis methods for classification of Phyllanthus chemical fingerprint: Unsupervised vs. supervised pattern recognition technologies. Anal. Bioanal. Chem. 2015, 407, 1389-1401. [CrossRef] [PubMed]

24. Guo, J.R.; Chen, Q.Q.; Lam, C.W.K.; Wang, C.Y.; Wong, V.K.W.; Xu, F.G.; Jiang, Z.H.; Zhang, W. Application of artificial neural network to investigate the effects of 5-fluorouracil on ribonucleotides and deoxyribonucleotides in HepG2 cells. Sci. Rep. 2015, 5, 16861. [CrossRef] [PubMed]

25. Kakito, H.; Ohkubo, T.; Kagawa, Y.; Inagaki, S.; Sumida, K.; Ooi, K.; Higashigawa, M.; Sakurai, M. Effects of 5-fluorouracil and a combination of tegafur and uracil (UFT) on nucleotide metabolism in L1210 ascites tumor. Cancer Investig. 1993, 11, 530-533. [CrossRef] [PubMed]

26. Chu, E.; Koeller, D.M.; Johnston, P.G.; Zinn, S.; Allegra, C.J. Regulation of thymidylate synthase in human colon cancer cells treated with 5-fluorouracil and interferon-gamma. Mol. Pharmacol. 1993, 43, 527-533. [PubMed]

27. Maley, G.F.; Maley, F. The Purification and Properties of Deoxycytidylate Deaminase from Chick Embryo Extracts. J. Biol. Chem. 1964, 239, 168-176. [PubMed] 
28. Mah, V.; Alavi, M.; Marquez-Garban, D.C.; Maresh, E.L.; Kim, S.R.; Horvath, S.; Bagryanova, L.; Huerta-Yepez, S.; Chia, D.; Pietras, R.; et al. Ribonucleotide reductase subunit M2 predicts survival in subgroups of patients with non-small cell lung carcinoma: Effects of gender and smoking status. PLoS ONE 2015, 10, e0127600. [CrossRef] [PubMed]

29. Zhou, B.; Yen, Y. Characterization of the human ribonucleotide reductase M2 subunit gene; genomic structure and promoter analyses. Cytogenet. Cell Genet. 2001, 95, 52-59. [CrossRef] [PubMed]

30. Chou, T.C.; Motzer, R.J.; Tong, Y.; Bosl, G.J. Computerized quantitation of synergism and antagonism of taxol, topotecan, and cisplatin against human teratocarcinoma cell growth: A rational approach to clinical protocol design. J. Natl. Cancer Inst. 1994, 86, 1517-1524. [CrossRef] [PubMed]

31. Chou, T.C.; Talalay, P. Quantitative analysis of dose-effect relationships: The combined effects of multiple drugs or enzyme inhibitors. Adv. Enzyme Regul. 1984, 22, 27-55. [CrossRef]

32. Guo, J.R.; Chen, Q.Q.; Lam, C.W.; Zhang, W. Effects of karanjin on cell cycle arrest and apoptosis in human A549, HepG2 and HL-60 cancer cells. Biol. Res. 2015, 48, 1. [CrossRef] [PubMed]

Sample Availability: Samples of Phyllanthus amarus Extract are available from the authors.

(C) 2016 by the authors; licensee MDPI, Basel, Switzerland. This article is an open access article distributed under the terms and conditions of the Creative Commons Attribution (CC-BY) license (http://creativecommons.org/licenses/by/4.0/). 